\title{
Augmenting adoptive $T$ cell therapy through universal chimeric costimulators
}

\author{
Ken-ichi Hanada*, Prachi Bagadia, Qiong Wang, Kayla Griffith, James Yang \\ From Society for Immunotherapy of Cancer 28th Annual Meeting \\ National Harbor, MD, USA. 8-10 November 2013
}

Adoptive transfer of Tumor Infiltrating Lymphocytes (TIL), T-cell receptor (TCR)-transduced PBL and Chimeric Antigen Receptor (CAR)-transduced PBL have proven to be clinically effective. CARs have evolved by introducing cytoplastic costimulatory domains. Higher cytokine secretion and longer persistence of CARtransduced T-cells in vivo imply important roles of costimulatory signals. In contrast, costimulation of TIL or TCR-transduced PBL in vivo relies on the expression of costimulatory receptors on T-cells and ligands on tumor cells or antigen presenting cells (APCs). One way to give $T$-cells their desired costimulation signal independent of the endogenous receptor/ligand expression would be to introduce a fusion molecule that is comprised of a receptor whose ligand is frequently expressed on tumor cells and an intra-cellular costimulatory domain. In a pursuit for a "universal costimulator" that is applicable to various tumors, we produced fusions of $\mathrm{CD} 2$ and various costimulators such as CD28, 4-1BB, ICOS, CD27 and OX-40 (Figure 1). CD2 is the receptor for CD58 that is expressed on various tumor cells. Since CD2-CD58 complex localizes to the Supramolecular Activation Complex (SMAC) on activation of TCR, CD2-costimulators may signal in a TCR-activation dependent manner. Human PBL were retrovirally transduced with genes that encode NY-ESO1-reactive TCR and each CD2-costimulator. In vitro co-culture assay showed higher IFN- $\gamma$ and IL-2 secretion by CD2-CD28 and higher IFN- $\gamma$ by CD2-OX40. To examine the in vivo effect of these fusion costimulators, vascularized SK23 melanoma tumor was established in NOD scid gamma (NSG) immunodeficient mice and human CD8+ T-cells transduced with anti-NY-ESO1 TCR and each fusion costimulator were injected. Out of five costimulators tested, CD2-CD28 showed a significant

Surgery Branch, $\mathrm{NCI} / \mathrm{NIH}$, Bethesda, MD, USA

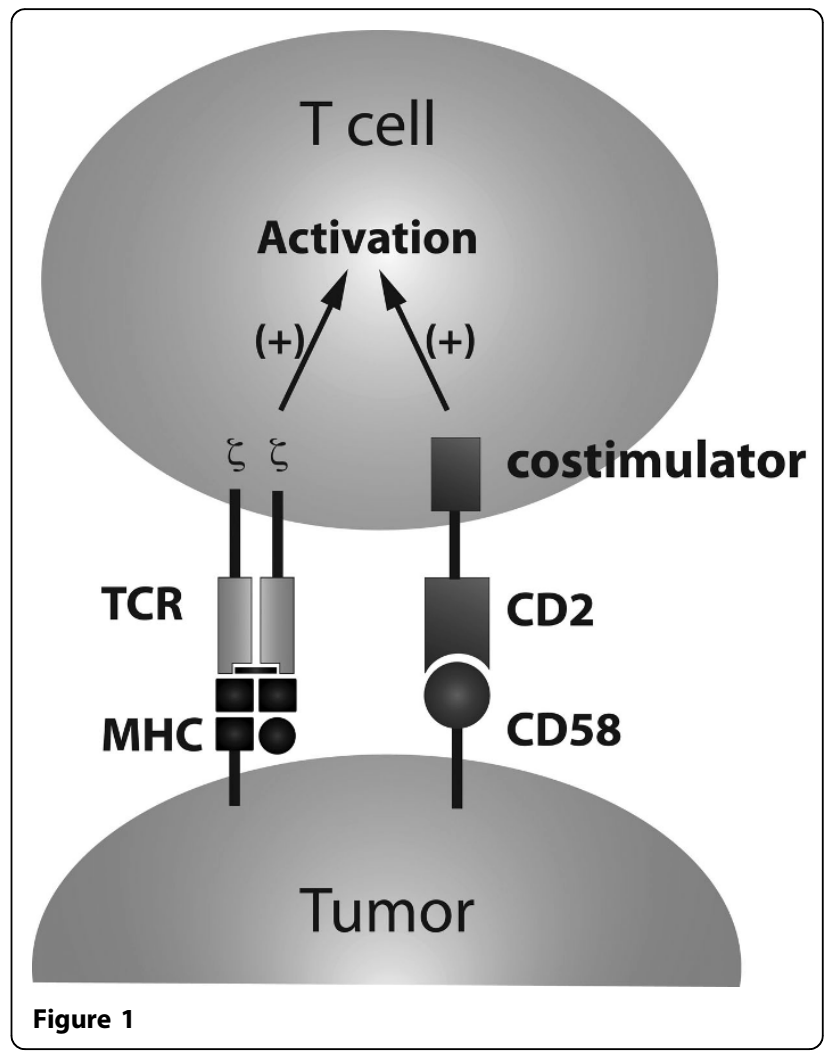

enhancement of anti-tumor effect. These results suggest that the CD2-CD28 costimulator may improve TIL and TCR-transduced PBL therapy.

Published: 7 November 2013

doi:10.1186/2051-1426-1-S1-P14

Cite this article as: Hanada et al:: Augmenting adoptive T cell therapy through universal chimeric costimulators. Journal for ImmunoTherapy of Cancer 2013 1(Suppl 1):P14.
C 2013 Hanada et al; licensee BioMed Central Ltd. This is an Open Access article distributed under the terms of the Creative Commons Attribution License (http://creativecommons.org/licenses/by/2.0), which permits unrestricted use, distribution, and reproduction in any medium, provided the original work is properly cited. 